\title{
THE REGULATIONS AND CONTROL OF ONLINE BETTING IN MALAYSIA
}

\author{
Guru Dhillon, ${ }^{1}$ Ng Yih Miin ${ }^{2}$
}

\begin{abstract}
The aim of this paper is to create awareness of the threats of online gaming to Malaysia and the International society in various areas such the involvement of money laundering via online gaming. It also includes suggestions of countermeasures and regulations that could be implemented in Malaysia. The paper will achieve this by having an insight of the accessibility of the online gambling to Malaysians and the law and regulations available in Malaysia to combat and cater the existence of online gambling. Law regulating gambling in general could be found in Betting Ordinance 1953 and Common Gaming House Act 1953. Account of initiatives taken to be taken by the Malaysian government will be in scrutiny in this paper. In addition, a review into the other jurisdictions from United Kingdom, United States and the available international law and regulations on online gambling such as the European Commission Green Paper: Online Gambling in the Internal 2011. Besides, the paper will also be viewing into the legislations of Commonwealth countries such as Australia on the online gaming such as the Interactive Gaming Act 2001. Nevertheless, there will be an in-depth view relationship of money laundering and online gambling. There will be suggestions of possible mechanism to regulate the online gambling activities in Malaysia in order to protect the interest of the people. Malaysia has legislations on gambling which do not specifically touches on online gambling and probably could be revised with new provisions in regulating the new entity, the online gambling. The practical implication of this paper is to emphasise the utmost importance of having awareness and revised strategies against the threat of online gambling which involved the unlimited access of internet and the inevitable necessities of new legislations and control mechanisms by the government authority to curb the peril. This paper could provide
\end{abstract}

Lecturer, Faculty of Business and Law, Multimedia University, 75450 Bukit Beruang, Melaka, contactable at 062523408.

2 Researcher, Faculty of Business and Law, Multimedia University, 75450 Bukit Beruang, Melaka contactable at 0126587122. 
useful information to practitioners, academics, policy makers and students. It could be a guide for any possible legislation to the current insufficiency.

Keywords - online gambling, enforcement, regulation, Malaysia, betting, wagering.

\section{Introduction}

Gambling has rooted in Malaysia since the early $19^{\text {th }}$ century when the Chinese traders and seamen came to Malaya. They brought the culture of gambling with them and had been regularly practising them during their free time. Nevertheless, the English Colonial master played a role in bringing different card games that have been popular in Malaysia as well as the Horse Racing game. It had been a famous activity in the Great Britain during the 1700's. This culture continues till now. Traditional gambling is no longer a new term in Malaysia. However, the latest trend that has been plaguing Malaysia since the late 1990's till now is the internet gambling. Internet gambling arises due to the blooming of the usage of internet. One of the most famous internet gambling is on the area of sports such as soccer and football.

This has then raised an alarming issue on the government of Malaysia as they could notice a sharp rise in the existence of "entertainment outlet" which is actually the den or vice of gambling. Then, the government realises further that there is a close relationship between internet gambling and sports. In many countries around the globe, internet gambling involving sports is common and legally recognised. Nevertheless, in a country like Malaysia and Singapore, it would be hardly legal and strongly against by the government. However, there are very few avenues for the gambling industry in Malaysia which are legalised. One of the few famous avenues is the Genting Highland Casino.

The twist of events happened in the later years where the Government of Malaysia came with an extraordinary but brave idea to provide license to certain vendors or business entity to carry out legal online gambling activities. One of the main players who attempted to obtain the very pioneer license is the tycoon Vincent Tan. This suggestion 
of legalising online betting came with mixed feelings and opinions from the different parties in Malaysia.

As the majority of the population of the country are Muslim, those who profess Islam as the religion, they are totally against the legalisation of online betting. The Islamic political party (PAS) was the first to object to the suggestion as they considered that the betting activities are against the principles of Islam. Whereas there were different opinions, for instance, the former Prime Minister of Malaysia, Tun Dr Mahathir Mohammad who strongly agreed and support the decision of the government. ${ }^{3}$

There are many arising concerns pertaining to the suggestion of legalising the online betting. This will be then discussed in the following section of this paper. In this paper, the issue focussed on the regulations in the pipeline in legalising online betting in the context of Malaysia and on the regulations made by other commonwealth countries and Malaysia comparatively.

\section{Regulations and Law Existing in Malaysia}

There are existing local law and provisions overseeing the issue of gambling in Malaysia. Gaming and wagering are regulated with extreme care in Malaysia. As the official religion of Malaysia is Islam, the authorities have been adhering to the prohibition on gambling as stipulated by the teachings of Islam. First and foremost, the Malaysia's Contract Act ${ }^{4}$ stipulated that any agreement by way of wager is considered as void with the exception that to certain prizes for horse-racing ${ }^{5}$. Nevertheless, there are exceptions whereby legal licensing could be provided to either the private companies or individuals. These exceptions are being controlled by the following statutes of law:-

(1) Pool Betting Act $1967^{6}$ (2) Betting Act 1953 (3) Lotteries Act 1952 (4) Common Gaming House Act 19537(5) Racing Club (Public Sweepstakes) Act 1965

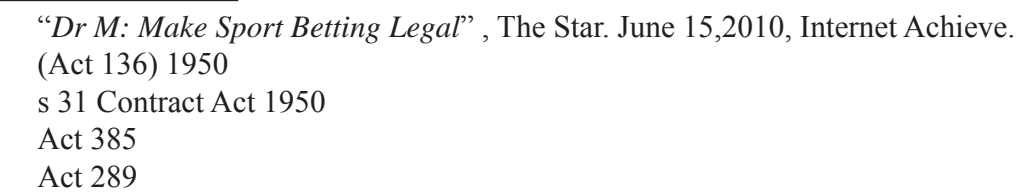


These provisions control the issuance of license to operate gambling activities of the respective kinds such as the casino, lottery or sweepstakes. Each of the kind is controlled by the respective statutes of law. There are restrictions to illegal gambling in the public such as stated in Common Gaming House Act 1953. The qualifications of items present at the scene of crime will be for arrest also being stipulated in the First Schedule of the Act.

There is no clear provision that regulate online gaming in the country. It is only deemed to be illegal to conduct the gambling activities without permission or license from the authority. ${ }^{8}$ The statutes which are currently available as stated above are not up to date as they are legislated during the era without the application of internet. Hence, the provisions are not sufficiently adequately in controlling the gambling activities in the advent internet usage in the modern world.

For instance, the definition of "common gaming house" provided under s2 of the Common Gaming House Act 1953 is confined to the word "place". However, the current trend of online casino is virtual casino which does not involve any physical place like the conventional casino which could be found in a premise. Worse still, most of the activities are conducted via the computer of the individual or patrons who visited the gambling website. The question will be whether the provision provided to define a "common gaming house" is adequate to include online casino.

In addition, the suggestion of the government to legalise the online gaming is not all negative as there are actually good reasons for supporting the idea. Firstly, it could function to reduce the amount of illegal bookies and at the same time acting as the double edge sword in gaining financial benefit by way of taxation and licensing fees. Through legalising online gaming, the number of illegal bookies could also be reduced along with the statistic of crimes related to gambling. As there are legal online gaming companies, government could also keep track of the patroniser of the websites as well as control the environment of the internet gaming by enforcing certain laws and regulations.

8 S27 Common Gambling House Act 1957 
Another concern is the uprising of the patronising of citizen into online casino which the government will have no full control of the situation. The uprising amount of cases will not be proportional to the effectiveness of enforcement measures. Hence, by legalising the online casino, the government could reduce the burden of another so called "crime" to the current overloading workload of the enforcement team.

\section{Regulations of the Online Casino}

This part will be on the suggestion to possibly regulate the legalised online gaming activities. These suggestions would be partly consist of endeavours carried out by other countries such as Australia and European Union in ensuring the public policy of the country is adhered to.

Australia has been experiencing ups and downs in the control of gambling. One of the most important legislations in the gambling history of Australia is the Interactive Gambling Act 2001. ${ }^{9}$ The act includes prohibition to interactive services provided to the customers in Australia as well as the designated countries, it provides for a complaint-based system to meet the needs of providing intelligence and information about prohibited Internet gambling service provided to customer in Australia. The act is applicable to services is provided in Australia, whereby it will be under the Australian police force duty to arrest. The Australian government will also filter the ISPs of the internet gambling services and inform the ISP provider of any infringement. The government will then negotiate with these companies on the necessary filtering procedures. This is a good law in the way that the Australian government has initiatives in protecting the Australia nationals from the negative effect of internet gambling.

\section{i) Australia Productivity Commission}

On the $23^{\text {rd }}$ June 2010, the Australian Productivity Commission released its report on Gambling. ${ }^{10}$ The report shows a significant advancement in the Australian gambling regulation as compared

\footnotetext{
Act No. 84 of 2001

10 Addisons Focus Paper, "Productivity Commission Draft Report on Gambling (October 2009) - What does this mean for the online gaming sector?" http:// www.pc.gov.au/projects/inquiry/gambling-2009/draft (accessed on 4th of February 2011)
} 
to the previous Draft Report published in October 2009. The commission is set up by the Australian government to give a concise report on the gambling industry concerning matters such as the implications of the new invention such as Internet on the convention regulations and law in Australia as well as the suggestions of good laws that could be legislated in Australia.

There are several key findings relevant to this paper. Firstly, the Australian Productivity Commission or APC found from the research that the Internet gambling does have benefits and at the same time poses a risk immense social risk in the society. Hence, there should be a proper regulation to control online gambling. In addition, the commission also pointed out that the current Interactive Gambling Act 2007 has barely being effective in reducing the demand for online gaming activities in Australia and the effectiveness is deemed to reduce over the time. It is also found that the prohibitions applied by the Interactive Gambling Act (IGA) do not provide adequate protections for the Australian online gambler. ${ }^{11}$ Most importantly, the commission emphasised on the concern of the flow of revenues and currency out of Australia to the offshore casinos which obviously has been shown to be non-beneficial to the economy of Australia. Based on the commission research is found that the consumption of Australian customers to the international online gambling websites has staggering increase. The statistics has equally represented that the Interactive Gambling Act has not effectively reduced the demand of the Australians in online betting.

In this respect, the commission to the legislator suggested to legalise online gambling but imposes minimal restrictions, so that the government could be able to gain benefit from it. In conclusion, the commission found that online betting has it special benefits but also poses risk to the society. The findings of potential harm posed by the online betting should be coupled with necessary regulations and law so that it could minimise the harm but not with pure restrictions to online gaming. It is also suggested by the commission that there should be a gradual liberalisation to the restrictions on online gambling starting with the low risk services such as poker card games. Other suggestions are that other gambling forms

11 Online Gaming -“ Australian Productivity Commission Final Report on Gambling” (June 2010). 
being exempted from IGA should be subjected to some regulatory procedures such as display the information on problems of gambling and automated warning on the potential pattern of play.

To date, the Australian government absolutely is not supporting the idea of liberalisation of online betting. Thus, the IGA prohibition of internet betting is to stay for now. The rejection of the suggestions of the commission does not actually prove the entire inadequacy and is relevancy of the paper. There are still many good suggestions to be picked up by Malaysia and Singapore that are in the pipeline to legalise the online betting services.

As summary to the above context, the initiative of the Australian government in restricting citizens from using the high risk gambling services is a good policy which could be likewise applied in Malaysia. This initiative could help to reduce risk and harm to the citizens while the government gain economical benefits from the gambling activities. Total restriction to online gambling has proven will not be able to reduce the demand of the online gambling.

\section{ii) Green Paper of EU}

The following section of this paper will be examining the suggestion provided by European countries as well as the European Union Commission on the restrictions and liberalisation of Internet betting. European Commission has published a report on the online gambling in the Internal Market. ${ }^{12}$ The purpose of this paper was to provide information and suggestions to curb the blooming number of both illicit and unauthorised on-line gambling to the citizen of European Union.

In the context of European Union, there are two extreme extents of approach fostered by the member. One of the extreme extents is by banning offer of certain online gaming or even banning it entirely. Certain states, however adopt an open market policy. From the research of EU, the on-line gambling services yearned to grow and will continue to double by year 2013. The consistency of the regulations on online gambling in Europe is barely satisfactory with the different approach applied by the different member of the state.

12 Green Paper "On on-line gambling in the Internal Market", European Commission. SEC(2011) 321 final” (Accessed on 24 $4^{\text {th }}$ March 2011) 
Due to the advent of internet and the fast paced growth of online gambling opportunities coupled with the inconsistent regulations and non-uniform enforcement of the different member of the states, it is inevitable and nearly favourable for the development of a great number of unauthorized cross-border markets. It may consist of the black market as well as the "grey" market. ${ }^{13}$ Hence, it is suggested that there should be a synchronized of legislation in providing security to the entire European Union society and not a non-uniform legislation.

As this paper discusses on the staggering growing amount of gaming revenues, the Green Paper provides an insight of the statistics. It was measured on the basis of Gross Gaming Revenue ${ }^{14}$ and was approximate $€ 75.9$ billion. It is $7.5 \%$ of the entire gambling market.

\begin{tabular}{|c|c|c|c|c|}
\hline & $2003 / €$ bn & $2008 / €$ bn & $2012 / €$ bn & Project Increase \\
\hline Internet & 4.8 & 5.9 & 7.32 & $152.5 \%$ \\
\hline Mobile Phones & 0.78 & $\mathrm{n} / \mathrm{a}$ & 3.51 & $450.0 \%$ \\
\hline
\end{tabular}

Figure 1. Projected increase in three main categories of remote gambling $^{15}$

\section{iii) Cross Border Treaty: Treaty on the Functioning of the European Union (TFEU)}

One of the important provisions in TFEU is Article 56 where it prohibits restrictions on the freedom to provide service to other Member States. It functions to protect the economic activity that falls under the scope of the Treaty. ${ }^{16}$

For instance, any services offered by electronic method will be restricted through the national legislation of the Member states disallowing the online services to consumer in the country. It created

13 Operators of the online gambling that is duly licensed in one or more Member States by providing services to citizen of certain country without complying to the existed law of the country.

14 Stake prizes but including bonuses

15 European Commission "Public consultation on on-line gambling in the Single Market" SICL study, page 1407 http://ec.europa.eu/internal market/services/gambling en.htm (accessed on February 21, 2011).

16 Case C-275/92, ECR 1994 Page I-01039 
a hindrance to the freedom as providing service or receiving service from the supplier established in another Member State. ${ }^{17}$

Allowance is expressly provided for in Article 51 and 52 of TFEU or is being justified in accordance to the case law for the interest of the public. In order to preserve the interest of the public, there is certain number of provisions under the consumer protection and the prevention of fraud on gaming would also be applicable.

A very vital point in providing a regional protection to ASEAN or Asian countries is to come out with a treaty on having consensus on websites that could be accessed by the people in Malaysia. Failure of the restrictions occurs when there is lack of diplomacy ties or consensus with other countries that provide the online gaming services. The internet providers in these countries will have to abide to the treaty as it has been effectively incorporated in to the local law. This is another important point is where the treaty must be treated supreme. Thus, one of the methods to ensure the treaty is effective is to include the clause inclusion compelling of the local law into the treaty.

Additionally, with the help of the joint co-operation of these countries, the sharing of information on identification of citizens for the use of identification would be made easy. Any foreigners or online user that would like to subscribe to certain online gambling services will have to provide their personal details including the passport number as well as the social security number. Hence, in coping with any frauds or scam, the information of the users will be shared among the members of the consensus and arrest could be made as that will assist the Interpol as well as other agencies in tracking down the criminal or suspects.

Other than the above discussed provisions, the EU also worked together in sharing details of the legal, authorised and licensed service provider of gaming in the respected countries. This will help the members of the consensus to identify providers which will likely to provide safe trade to the people and also to protect the consumers from being framed into the fraud and crime by syndicates online. This initiative will most likely reduce the risks of the online gamblers.

17 Gambeli Case C-243/01, ECR 2003, Page 1-13031. 
It was stressed in the paper that one of the reasons where online gaming might contribute to the rise of fraud by operators is because of the lack of direct contact between the consumer and the online gambling operators. It is a substantial risk as compared to the traditional gambling market. ${ }^{18}$

The other problem as pointed out in the paper is on the risk of addiction by the users. It was known that the ability to permanently access to the online gambling services had significantly increased the risk of the consumer to suffer from the addiction of the games. The lack of control and the high amount of offers will increase the prevalence of gambling addictions. For example, most of the cyber gamblers participation be anonymously and in isolation. They could either play or participate in the game with other gamblers or played alone just behind computers. This will create an absence of social control towards the activities and will then develop gambling addiction. ${ }^{19}$

\section{iv) Online Gambling Services Establishment in EU}

In reference to Article 49 TFEU, the definition to the word 'establishment' is being too wide too wide. There are several different understandings to the word. Firstly, it will mean to allow an EU national to take part in the economic life of another Member State and profit from the participation. Besides, it will also involve the contribution of the EU nationals to the economic growth and social interpenetration within the Community. ${ }^{20}$

According to e-commerce perspective, ${ }^{21} \mathrm{a}$ business entity that provides information society services will be considered as an established business entity where there is economic activity interest. National law will then hold certain threshold on the number of licenses that will be permissible or even banned it entirely. Hence, providers of the services will have applied to the license in each of these Member States so as to be considered legal establishment.

18 Case C-42/07, cited above, $\S 70$. As regards face-to-face customer identification and age verification, see questions 16 and 24 .

19 Case C-46/08, ECR [0000], Page I-0000, §103. As regards factors linked to problem gambling, see questions 17 and 19.

20 Case C-55/94, ECR 1995, Page I-4165

21 OJ L 178, 17.0.2000, p. 1 


\section{v) Problem Gambling in EU}

Gambling problems exist in European well as the other counterpart around the globe. Hence, in order to assess the severity of the problem gambling problem in a certain population, there are two inventions of prevalence studies which could be implemented. They are the DSM-IV ${ }^{22}$ and SOGS. ${ }^{23}$ They are being carried out to screen and identify the risky gamblers. This test is being used as the standard test in eight Member States ${ }^{24}$ extensively as well as another seven countries ${ }^{25}$ which were carried out on limited scope. There are several main factors being identified by these studies that highly influence the problem of gambling.

Firstly, it is the event frequency. It is regarding the time gap between one set of game from the other. It is of the opinion that, the gap between the game and the risk of placing a stake has a close relationship. Secondly, it is the payout interval. It is the time between placing of stake and announcement of the result. It is known that the briefer the payout interval greater risk there will be .Other than that, the accessibility and social environment also play an immense role in on gambling. What added to the graving situation is the extensive commercial advertisement that entices people to continue with betting or to even get involved in betting for the first time. It was also known that different types of games or different kinds of bets will cause different risks to the players.

There are also some suggestions of instrument that could be applied to handle the gambling problem. First of all, the age limit could help to confine the risk to just certain age group of people especially for those who do not possess the maturity to make good decisions. There other options beings suggested like the self-limitation in the

22 Diagnostic and Statistical Manual of Mental Disorders, 4th ed. for pathological gambling, (American Psychiatric Association, 1994). A publication of the 5th edition of Diagnostic and Statistical Manual of Mental Disorders (DSM-V) is foreseen for May 2013.

23 The South Oaks Gambling Screen, Lesieur \& Blume, 1987. Both tools (DSM and SOGS) also exist in versions adapted to adolescents: DSM-IV-J (juvenile), DSM-IV-MR-J (multiple response-juvenile) and SOGS-RA (revised for adolescents).

24 BE, DK, EE, FI, DE, NL, SE and UK.

25 ES, HU, IT, LT, RO and SK 
aspect of financial and time as well as self-exclusion. There should be restrictive guidelines on the amount of leverage and risk that could be imposed on the person subjective to the financial standing and other factors.

The other suggestion is by providing information or warnings that could be applied online about significant risk to the particular player. There should be a mechanism where warning will be given when there is certain trait or pattern of play that may contribute to debts and over-limit loss. The commission also suggested the banning of credit use. This could prevent exceeding self limit situation where credit overdraft runs out of hand. It is also part of the online operator duty to ensure that the customers do not excessively indulge in the games by promoting some educational tutorials. Warnings should also within every short period of break. The authority could narrow the bad gaming attitudes by providing a restrictive clause on certain forms of games or bet with a high risk to the consumer.

\section{vi) Public Order: Prevention of Fraud}

The green paper also provided a valuable piece of information on the prevention of fraud in the process of legalising online gambling. Fraud is no longer an uncommon word when it comes to online gambling. The EU law aims to protect the consumer from any form of fraudulent activities regardless of players or operators. This could be closely associated with the identity theft and match fixing issues that is alarming these days. ${ }^{26}$

The commission has identified three main types of fraud. Firstly, the players do not receive their winnings and capital. It could normally be seen in illegal lottery scams. Secondly, another type of fraud is when either the companies sold the identities of the clients to the unauthorised parties or when the unauthorised parties took part in a heist or hacking process in order to obtain the information of the customer. Lastly, to make the matter worse, these parties might even tamper the credit card information in order to obtain fraudulent income from the action. All the fraudulent activities should be taken into serious consideration and should be coped without hesitations.

26 E.g. criminal organisations based in China or Croatia have been involved in match fixing in BE, DE and FI. 


\section{vii) Another Concern of Online Gambling: Prevention of Money Laundering}

In the Green Paper of EU, there are two different polarity of money laundering being mentioned. Firstly, it is the complex transnational operations where is it carefully designed to conceal the original criminal involving large amount of money by making the people and property made to be legally recognised. The other type of money laundering is when the activity of concealment extended to all range of sum no matter is big amount or small amount. Inevitably, there is almost no evidence suggesting that the online gaming in Europe is involving any money laundering activities.

In practice, the online gambling firms could bank in the winnings as amount unused funds into an account once the original bet is made. This could further complicate the process of detecting money laundering activities when these players could register several different accounts with the same operator. In peer to peer games such as e-poker, the money launderer could use the nature of the game where money or value could be transferred from one player to another when a win or lose game materialized. This is online chip dumping. For instance, player could deposit a large amount of illegal money from illegal proceeds and dumps the credit to the other player who is his accomplice. Another important issue of money laundering in online gaming is the involvement of e-cash which is also similar to the Stored Value Cards, ${ }^{27}$ as these methods of payment will involve no post-purchase monitoring.

\section{In the Context of Malaysia}

As this paper has brought the issues and suggestions of reform from the different jurisdictions around the world about the enforcement of online casino, the following will be the suggestions on measures that could be taken to ensure the people in Malaysia will be protected when the online gambling is being legalised for the advantage of the economy of the country:-

\footnotetext{
$27 \quad$ A stored-value card refers to monetary value on a card not in an externally recorded account and differs from prepaid cards where money is on deposit with the issuer similar to a debit card.
} 


\section{i) First Issue: Money Laundering}

First and foremost, it is important for the government agency to limit the number of licensee of the online betting. There should be a specialised agency in dealing with the online gambling issues. Only those with the license will be allowed to be accessed in Malaysia.

Hence, the legal online gambling providers will have to comply with a list of restrictive order by the agency before being permitted to operate. In order to cope with money laundering in online gambling, there should be transparent client information to the government agency. The agency could then detect any possible money laundering activities from the sharing of information with other financial institution and international authorities such as the Anti-money Laundering bodies (AML).

Customer Due Diligence - the service provider should always only allow players holding a valid account to play. Information should be provided by way of application forms when the customer applied an account. All these information will have to be provided to the government agency for analysis. These providers should give full co-operation to the AML as well and follow strictly to the rules and regulation provided. The due diligence exercises conducted by the internet providers include among others identifying deposit/trades analysis, abnormalities of player behaviour or patterns and the initiation of cybercrimes arrest policy.

Payment Controls - the service providers should always ensure the consistency of the payout and payment. They should always make sure that they have a control over the credit card numbers and other personal data of the players.

In addition, there should be a control of credit that could be provided to these players according to their financial soundness and security background of the players. Certain procedures such as deposit and charges should be applied to ensure that there will be no extreme debts cultivated. These authorised casinos will have to comply with the standards stipulated by the government agency.

Besides, there should be a strong link of co-operation between the banks involved in the transactions and the government agency in 
order to control any fraudulent activities as well as money laundering from being rooted in services. It would also be wise to establish a highly secured transaction pipeline for the consumer in order to protect the consumers from possibly risk of crimes and fraud as well as identity theft.

Operational Controls- the internet gambling providers should always have the age verification lists as well as other lists used by the banks to identify terrorist and politically exposed persons (PEPs). One of the best examples is the World $\mathrm{Check}^{28}$ as well as the European Sports Security Association's (ESSA) list. ${ }^{29}$ The providers should always adhere to the procedures to keep track of every transactions and activities. They must always submit the Suspicious Activity Report (SAR) to the national Financial Intelligence Units (FIU).

\section{ii) Enforcement and Related Matters}

There are many concerns of illegal trans-national market to be accessed by the consumer. The main reason to this concern is when there is no effective enforcement of law. It is a vital point to ensure that there is effective enforcement in ensuring that the government could achieve the goal to protect the public interest when passing a bill on gambling policy.

Gambling policy - there should be joint organisational structures among the countries throughout the globe in carrying out regulations, licences and supervision of online gambling.

The function of the authority is to issue license to the eligible applicants. There should be a control over the number of licensee. A strict examination and requirements shall be fulfilled by the licensee before the issuing of license. This organisation should ensure the maximum amount of certainty when it comes to the financial information as well as other information of the providers.

28 World Check. "Political Exposed Person and Compliances". Thompsom Reuters.http://www.world-check.com/politically-exposed-person-pep-compliance/ (accessed March 2, 2011)

29 European Sports Security Association. "Crying Foul: 12 Myths About Sports Betting” .European Sports Security Documents. http://www.eu-ssa.org/Home/ tabid/36/Default.aspx. (Accessed on the March 15,2011) 
The authority should also be given the power to suspend and revoke any licences when the providers disobey any of the guidelines. The authority must control and carry out supervision the financial control as well as the technical aspect in monitoring of the activities and complaint of the customers.

The providers shall always maintain transparency towards the government agencies as well as other regulatory bodies. Information of the licensee holder, players as well as the fraudulent operator should be share among the agencies and bodies. It would be a good practise to carry out public campaign creating awareness of the negative effects of gambling to the society.

Providers of internet gambling, either domestically or internationally should be applying for the license of operation via the government agency in Malaysia. They should be able to provide detailed information of the directors as well as all the members involved in the entire co-operation. It will have to be coupled with the assurance from government entity from the country of operation or even private established companies. There should be a strong link of security where these companies will not be involved in fraudulent activities. These companies should also provide information on the financial background of the companies for the past years as well as providing a considerable amount of deposit before the application could be processed.

These companies should abide to the directive of the government agency on the restrictions of players as well as the amount of money should be involved in the particular activity for each member. These websites should allow the government agency to be the first in line control gate to the players where security measure involving these government agencies could be incorporated in the website. There should be a clear and transparent flow of information by these companies to the Interpol and government agencies involved.

\section{iii) Control of ISP and Payment}

The payment and communication providers give lives to the online gambling service. Hence, in order to restrict the illegal gambling services, the following will be the possible measures to be taken:- 
Domain Name System (DNS) filters- Filtering DNS is a mechanism where it could ensure that the potential customer is being prevented to patronise illegal pre-listed sites or being directed to another website. So, there will be a list of banned website or DNS where no one using the particular internet provider will be able to access.

In the context of Malaysia, there will be a need to control the flow of internet gambling services that could be accessed by the people. It could be done by restriction via DNS as well as the IP address which will be address later in this paper. Another way to restricting the consumers from being addicted to online gambling is by restricting the group of people that could be involved in the game. Firstly, there should be a restriction of age group. This is where the players have to register to the government agency and also to provide the information to the providers on their age and. This helps to ensure that the underage citizen will not be involved in the gambling activities. Maturity of the player is also ensured and thus one can decide reasonably while gambling.

In addition to that, in order to ensure the reliability of this process, all consumers who desire to access to the gambling services will have to apply to the government agency for their financial status, security background as well as basic details. This measure is to ensure that only the qualified group of people is being allowed to be involved in these activities. This could restrict the high risk people for instance, low income as well as past addictions or group of people who are prone to debts from involving in the activities. Hence, this government agency could act as the control to the flow of consumers into websites that provide the service. There will be a compilation of information of these players as well as for the player; they will receive a highly encrypted identification card that will allow them to join these websites.

Internet Protocol (IP) blocking- Every device that is associated with the public internet access will have its very own identification called as IP address. This will include the hostname. Hence, with this blockage, it could prevent the connection between a serve with one or more IP addresses. 


\section{Conclusion}

After all, it will be the legislator of the country who will formulate the best provisions in protecting the interest of the people. It would be a valued opinion that restrictions will not result in the reducing of the people in involving in the activities. It would be ultimately the choice of the people that finalised the result of the entire picture.

Regulations and law could be put into place in order to ensure the advantage to be gained from online gambling as well as the protection of the people fromits risks. There is no absolute perfect law but there are great initiatives towards the better future. Hence, it is of the opinion that online gambling indeed is a double edge sword. The government would gain the benefit from these activities and at the same time taking extra due care on against the harm of gambling.

\section{Bibliography}

Green Paper. (2011). "On on-line gambling in the Internal Market", European Commission. SEC 321 final, 24 $4^{\text {th }}$ March 2011. http://www.ec.europa.eu/internal_market/services/gambling en.htm (accessed on April 15, 2011).

Dr M: Make Sport Betting Legal. The Star. 15 ${ }^{\text {th }}$ of June 2010.

Council of Australian Commission (June 2010). Online Gaming - Australian Productivity Commission Final Report on Gambling.

Khalid Ali. European Sports Security Association Confirms: No Suspicious Betting Behaviour During 2010 FIFA World Cup(2010). http://www.eu-ssa.org/Home/tabid/36/Default.aspx (accessed on the March 21, 2010).

Mark D. Griffiths, Richard T.A. Wood and Jonathan Parke. Cyber Psychology \& Behavior. August 2009, 12(4): 413-421. doi:10.1089/cpb.2009.0062.

Wardle, Heather. British Gambling Prevalance Survey 2007. United Kingdom: Gambling Commission, 2007. 
Hörnle, Julia and Zammit, Brigitte. Cross Border Online Gambling Law and Policy. United Kingdom: Edward Elgar Publishing, 2010.

Frey, James H. Gambling: Socio Economic Impacts And Public Policy: Federal Involvement in U.S. Gaming Regulation. The Annals of The American Academy of Political and Social Science, 1998. 556 Annals 138. 